\title{
Influence of Charge State and Sodium Cationization on the Electron Detachment Dissociation and Infrared Multiphoton Dissociation of Glycosaminoglycan Oligosaccharides
}

\author{
Jeremy J. Wolff, ${ }^{a}$ Tatiana N. Laremore, ${ }^{b}$ Alexander M. Busch, ${ }^{d}$ \\ Robert J. Linhardt, ${ }^{b, c, d}$ I. Jonathan Amster ${ }^{a}$ \\ ${ }^{a}$ Department of Chemistry, University of Georgia, Athens, Georgia, USA \\ ${ }^{b}$ Department of Chemistry and Chemical Biology, Rensselaer Polytechnic Institute, Troy, New York, USA \\ ${ }^{c}$ Department of Chemical and Biological Engineering, Rensselaer Polytechnic Institute, Troy, New York, USA \\ ${ }^{\mathrm{d}}$ Department of Biology, Rensselaer Polytechnic Institute, Troy, New York, USA
}

Electron detachment dissociation (EDD) Fourier transform mass spectrometry has recently been shown to be a useful method for tandem mass spectrometry analysis of sulfated glycosaminoglycans (GAGs). EDD produces abundant glycosidic and cross-ring fragmentations that are useful for localizing sites of sulfation in GAG oligosaccharides. Although EDD fragmentation can be used to characterize GAGs in a single tandem mass spectrometry experiment, $\mathrm{SO}_{3}$ loss accompanies many peaks and complicates the resulting mass spectra. In this work we demonstrate the ability to significantly decrease $\mathrm{SO}_{3}$ loss by selection of the proper ionized state of GAG precursor ions. When the degree of ionization is greater than the number of sulfate groups in an oligosaccharide, a significant reduction in $\mathrm{SO}_{3}$ loss is observed in the EDD mass spectra. These data suggested that $\mathrm{SO}_{3}$ loss is reduced when an electron is detached from carboxylate groups instead of sulfate. Electron detachment occurs preferentially from carboxylate versus sulfate for thermodynamic reasons, provided that carboxylate is in its ionized state. Ionization of the carboxylate group is achieved by selecting the appropriate precursor ion charge state, or by the replacement of protons with sodium cations. Increasing the ionization state by sodium cation addition decreases, but does not eliminate, $\mathrm{SO}_{3}$ loss from infrared multiphoton dissociation of the same GAG precursor ions. (J Am Soc Mass Spectrom $2008,19,790-798) @ 2008$ American Society for Mass Spectrometry

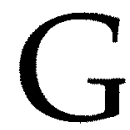
lycosaminoglycans (GAGs) participate in numerous important biological processes such as cell-cell signaling $[1,2]$, the regulation of biochemical pathways [3, 4], inhibiting proteolysis [5], and effecting angiogenesis [6]. GAGs also play an important role in pathogenic infections [7-9] and may undergo alteration in certain types of cancer [10]. Both intra- and extracellular GAG proteoglycans can be found in a wide variety of organisms, from bacteria to humans [11]. At the molecular level, GAGs are sulfated, linear carbohydrates consisting of alternating acidic sugar and basic sugar residues. GAG complexity arises through variable sulfation, $\mathrm{N}$-modification of the basic residues, and C5 stereochemistry of the hexuronic acid residues. There is significant interest in developing methods to determine the pattern of modification in GAG oligosaccharides because these are believed to influence the

Address reprint requests to Dr. Jonathan Amster, University of Georgia, Department of Chemistry, Athens, GA 30602-2556.E-mail: jamster@uga.edu biological function of the GAG molecule. Although 1D and $2 \mathrm{D}$ NMR can be used to determine the pattern and type of GAG modification [12], GAGs must be isolated from natural sources and may often not be available in the quantity and purity required for NMR analysis. Mass spectrometry is much more sensitive than NMR and can be used to examine mixtures, particularly when combined with online chromatography. A wide variety of mass spectrometry and tandem mass spectrometry (MS/MS) techniques have been developed to analyze this challenging class of molecules [13-20].

Recent work from this laboratory has demonstrated the analytical utility of electron detachment dissociation (EDD) [21] for the structural analysis of negatively charged GAG oligosaccharides varying in length from tetrasaccharides to decasaccharides [22-24]. EDD produces more abundant glycosidic and cross-ring fragmentations for GAG oligosaccharides than are observed by more conventional dissociation methods such as collisionally activated dissociation (CAD) or infrared 
multiphoton dissociation (IRMPD). Moreover, it reduces the loss of $\mathrm{SO}_{3}$ from labile sites of sulfation compared to other methods of ion activation. This fragmentation behavior has been proposed to result from a radical anion that is formed from electron detachment and that yields product ions that are distinctly different from the dissociation products of closed shell anions via low-energy or threshold fragmentation methods such as CAD or IRMPD. As in electron ionization mass spectra, the location of the radical site is expected to influence the resulting fragmentation and observed products. Our prior results suggest that electron detachment occurs at a site of negative charge: carboxylate and sulfate groups. The charge of the precursor ion determines how many of these sites are ionized that are available as candidates for electron detachment. Thus the charge state of the precursor ion may have a significant influence on fragmentation and on the ions produced by EDD.

The charge state of the precursor ion has been shown to influence fragmentation of closed-shell ions. For CAD fragmentation of heparin-like GAGs, Zaia and colleagues demonstrated that glycosidic cleavages increased and $\mathrm{SO}_{3}$ loss decreased as the charge state of the precursor ion increased [25]. The work by Zaia et al. also demonstrated that the addition of $\mathrm{Ca}^{2+}$ to the precursor ion minimized $\mathrm{SO}_{3}$ loss during CAD of closed-shell ions. It is possible that replacing protons with monovalent cations such as sodium may also suppress $\mathrm{SO}_{3}$ loss in the dissociation of sulfated GAG oligosaccharides by EDD. In the present work, we examine the influence of charge state and sodium cationization on the EDD fragmentation of a GAG octasaccharide, and compare these products with those obtained by IRMPD.

\section{Experimental}

\section{Preparation of DS Oligosaccharides}

Dermatan sulfate (DS) octasaccharides were prepared by partial enzymatic depolymerization of porcine intestinal mucosa dermatan sulfate (Celsus Laboratories, Cincinnati, OH, USA). A $20 \mathrm{mg} / \mathrm{mL}$ dermatan sulfate solution in $50 \mathrm{mM}$ Tris- $\mathrm{HCl} / 60 \mathrm{mM}$ sodium acetate buffer ( $\mathrm{pH} 8$ ) was incubated at $37^{\circ} \mathrm{C}$ with chondroitin ABC lyase from Proteus vulgaris, EC 4.2.2.4 (Seikagaku, Japan). The absorbance at $232 \mathrm{~nm}$ was monitored to determine when the digestion was $50 \%$ completed. The digestion mixture was then heated at $100{ }^{\circ} \mathrm{C}$ for $3 \mathrm{~min}$. High-molecular-weight oligosaccharides and the glycosidic enzyme were removed by ultra-filtration using a 5000 MWCO membrane. The resulting oligosaccharide mixture was concentrated by rotary evaporation and fractionated by low-pressure GPC on a Bio-Gel P10 (Bio-Rad, Richmond, CA, USA) column. The fraction containing DS octasaccharides (dp8) was desalted by GPC on a Bio-Gel P2 column and freeze-dried [26]. Further purification of DS dp8 was carried out using strong anion exchange high-pressure liquid chromatog- raphy (SAX-HPLC) on a semi-preparative SAX S5 Spherisorb column (Waters Corp., Milford, MA, USA). The SAX-HPLC fractions containing $>90 \%$ of DS dp 8 were collected, desalted by GPC, and freeze-dried. The solid was reconstituted in water and purified a second time by SAX-HPLC. Only the top 30\% of the chromatographic peak was collected, desalted, and freeze-dried. Concentration of the octasaccharide solution was determined by measuring the absorbance at $232 \mathrm{~nm}(\varepsilon=$ $3800 \mathrm{M}^{-1} \mathrm{~cm}^{-1}$ ). The resulting fraction containing DS dp8 was characterized by PAGE, ESI-MS, and high-field nuclear magnetic resonance (NMR) spectroscopy.

\section{Mass Spectrometry Analysis}

Experiments were performed with a 9.4 T Bruker Apex Ultra QhFTMS (Billerica, MA, USA) fitted with an Apollo II dual source, a $25 \mathrm{~W} \mathrm{CO}_{2}$ laser (Synrad model J48-2, Mukilteo, WA, USA) for IRMPD, and an indirectly heated hollow cathode for generating electrons for ECD and EDD. For studies requiring sodium, the octasaccharide was introduced at a concentration of 150 $\mu \mathrm{M}$ in 50:50 methanol: $\mathrm{H}_{2} \mathrm{O}$ with $1 \mathrm{mM} \mathrm{NaOH}$ (Sigma, St. Louis, MO, USA) by electrospray ionization (ESI) in negative-ion mode. To produce abundant $[\mathrm{M}-3 \mathrm{H}]^{3-}$ ions, the octasaccharide was introduced at a concentration of $20 \mu \mathrm{M}$ in 50:50:1 methanol: $\mathrm{H}_{2} \mathrm{O}$ :formic acid. All sample solutions were infused at a rate of $120 \mu \mathrm{L} / \mathrm{h}$.

For the EDD experiments, precursor ions were isolated in the external quadrupole and accumulated for 1-4 s before injection into the FTMS cell. The isolation/ cell fill was repeated up to six times. The selection of the precursor ion was further refined by using in-cell isolation with a coherent harmonic excitation frequency (CHEF) event [27]. The precursor ions were then irradiated with electrons for $1 \mathrm{~s}$. For electron irradiation the cathode bias was set to $-19 \mathrm{~V}$, the extraction lens was set to $-18.5 \pm 0.5 \mathrm{~V}$, and the cathode heater was set to 1.6 A. Ions were excited with an RF frequency chirp that covered the range of $100-2000 \mathrm{~m} / \mathrm{z}$. In all, 24 acquisitions were signal averaged per mass spectrum. For each mass spectrum, $512 \mathrm{~K}$ points were acquired at a $2.4 \mathrm{MHz}$ digitization rate, padded with one zero fill, and apodized using a sinebell window. Background spectra were acquired by leaving all parameters the same but setting the cathode bias to $0 \mathrm{~V}$ to ensure that no electrons reached the analyzer cell. Background spectra were not subtracted from the EDD spectra, but were used to ensure that very few products were formed during ion accumulation and isolation. IRMPD spectra were acquired using the same experimental setup as EDD, but replacing the electron irradiation event with a laser pulse. For IRMPD, ions were irradiated for $0.01-$ $0.2 \mathrm{~s}$ with beam attenuation set to pass from 40 to $60 \%$ of full power. External calibration of IRMPD and EDD mass spectra produced mass accuracy of 5 ppm. Internal calibration was also performed using confidently assigned glycosidic bond cleavage products as internal calibrants, providing mass accuracy of $<1$ ppm. Be- 


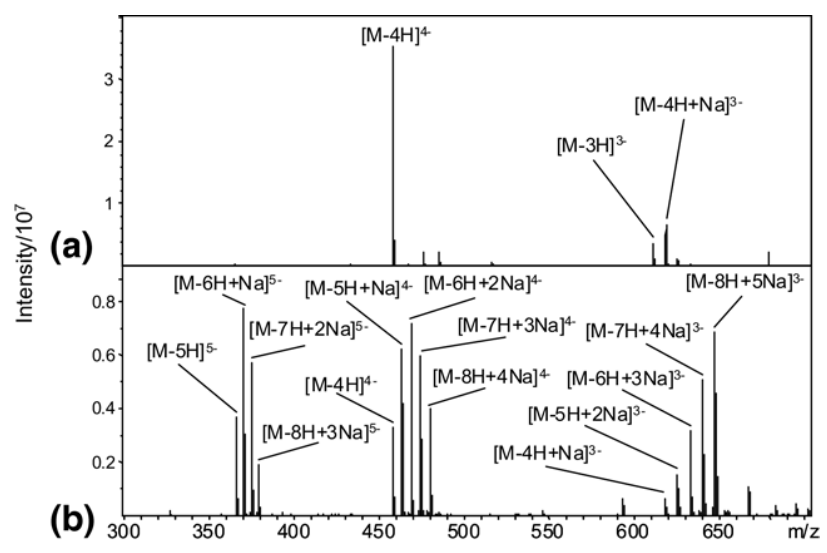

Figure 1. The influence of solution conditions on the observed ESI-FTMS spectra of DS dp8. (a) $15 \mu \mathrm{M}$ DS dp8 dissolved in 50:50 methanol: $\mathrm{H}_{2} \mathrm{O}$ with $1 \%$ formic acid results in no $\mathrm{Na} / \mathrm{H}$ heterogeneity and the formation of a $[\mathrm{M}-3 \mathrm{H}]^{3-}$ ion. (b) $150 \mu \mathrm{M}$ DS dp8 dissolved in 50:50 methanol: $\mathrm{H}_{2} \mathrm{O}$ with $100 \mu \mathrm{M} \mathrm{NaOH}$ results in abundant $\mathrm{Na} / \mathrm{H}$ heterogeneity.

cause of the larger number of low-intensity products formed by EDD, only peaks with $\mathrm{S} / \mathrm{N}>10$ are reported. Product ions were assigned using accurate mass measurement. For the work presented here, fragmentation of the DS octasaccharide is presented using a modification of the Domon and Costello annotation [28] that presents GAG fragmentation with $\mathrm{SO}_{3}$ loss and hydrogen rearrangement that is observed in EDD of GAGs [22].

\section{Results and Discussion}

DS dp8 has eight ionizable acidic sites: four carboxylic acid groups and four sulfate groups. This acidic molecule readily forms negative ions, but the charge state and $\mathrm{Na} / \mathrm{H}$ heterogeneity depend strongly on solution conditions. The influence of ESI solution conditions is shown in Figure 1a and $b$. The addition of 1\% formic acid to the ESI solution results in the mass spectrum shown in Figure 1a, in which abundant $[\mathrm{M}-4 \mathrm{H}]^{4-}$ and $[\mathrm{M}-3 \mathrm{H}]^{3-}$ molecular ions are observed, with only a low level of sodium cationization. The addition of 100 $\mu \mathrm{M} \mathrm{NaOH}$ in place of formic acid to the ESI solution produces the more highly charged $5^{-}$ion as well as the $4^{-}$and $3^{-}$ions. The presence of sodium cations in solution also results in the exchange of up to 5 protons by sodium cations, as shown in Figure 1b. Using these two solution conditions the influence of precursor ion charge $\left(3^{-}, 4^{-}, 5^{-}\right)$and sodium cationization $(0-4)$ on sulfated GAGs is examined.

\section{Influence of Charge State on EDD Fragmentation of $D S d p 8$}

EDD of the $[\mathrm{M}-4 \mathrm{H}]^{4-}$ and $[\mathrm{M}-3 \mathrm{H}]^{3-}$ precursor ions of DS dp8 produce many glycosidic and cross-ring cleavages that are also accompanied by the loss of $\mathrm{SO}_{3}$. No product ions are observed with loss of two equivalents of $\mathrm{SO}_{3}$ for any EDD mass spectrum, regardless of the charge state of the precursor ion. Product ions with $\mathrm{SO}_{3}$ loss generally occur as satellite peaks to similar fragments without $\mathrm{SO}_{3}$ loss, and are easily assigned because the pairs of peaks differ by the exact mass of $\mathrm{SO}_{3}, 79.957 \mathrm{u}$. Although products ions accompanied by $\mathrm{SO}_{3}$ loss are easily identified, they complicate the EDD mass spectrum by adding additional peaks and do not aid in deciphering the structure of the sulfated GAG. The additional complexity resulting from product ion $\mathrm{SO}_{3}$ is apparent in Figure 2, where many of the product ions accompanied by the loss of $\mathrm{SO}_{3}$ are present in the EDD mass spectrum of DS dp8. The $Z_{3}$ and $Y_{3}$ glycosidic cleavages are accompanied by $\mathrm{Z}_{3}-\mathrm{SO}_{3}$ and $\mathrm{Y}_{3}-\mathrm{SO}_{3}$ product ions, as well as many other product ions accompanied by the loss of $\mathrm{SO}_{3}$ as shown in Figure 2a. However, a much simpler EDD mass spectrum is observed from EDD of the $[\mathrm{M}-5 \mathrm{H}]^{5-}$ precursor ion (Figure $2 \mathrm{~b}$ ) because of the absence of satellite peaks from $\mathrm{SO}_{3}$ loss. As shown in Figure $2 b$, the $Z_{3}$ and $Y_{3}$ glycosidic cleavages are not accompanied by $\mathrm{SO}_{3}$-loss product ions. This behavior is observed throughout the EDD mass spectrum. The number of products accompanied by $\mathrm{SO}_{3}$ loss is similar in EDD of $[\mathrm{M}-3 \mathrm{H}]^{3-}$ and $[\mathrm{M}-4 \mathrm{H}]^{4-}$, i.e., no decrease in $\mathrm{SO}_{3}$ loss is observed when the precursor ion charge increases from $3^{-}$to $4^{-}$. In contrast, there is a dramatic decrease in the loss of $\mathrm{SO}_{3}$ for precursor ion charge $5^{-}$versus $4^{-}$or $3^{-}$, as shown in Figure 3a-c, respectively. Fragmentation accompanied by loss of $\mathrm{SO}_{3}$ is denoted with an open circle. For EDD of $[\mathrm{M}-3 \mathrm{H}]^{3-}$, 36 of the 88 observed cleavages are accompanied by $\mathrm{SO}_{3}$ loss, and EDD of [M
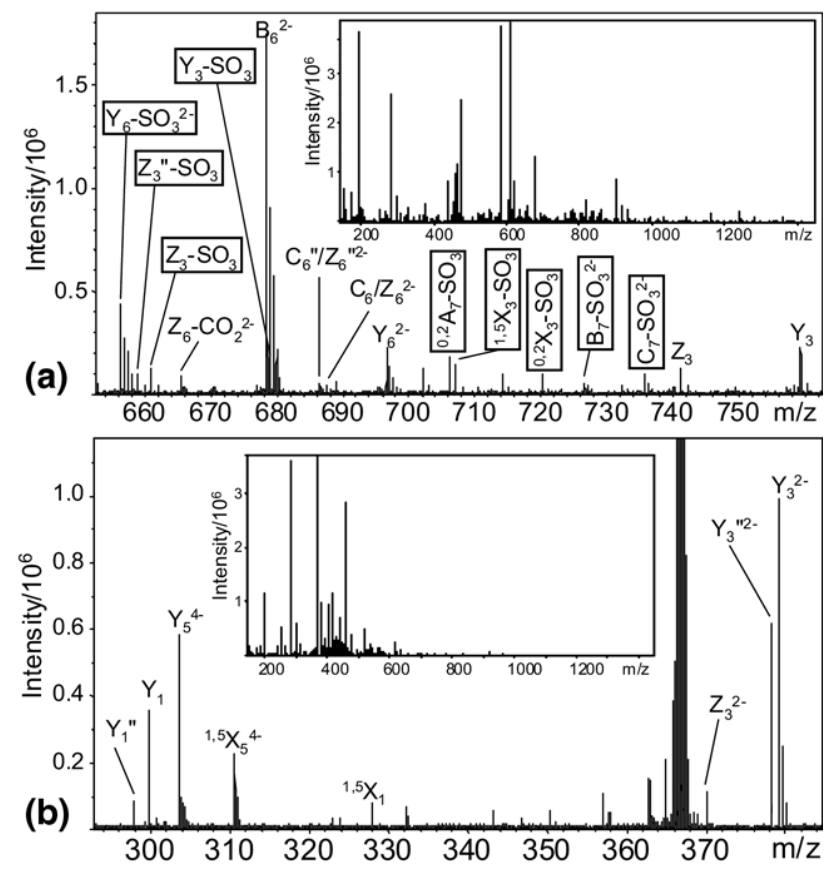

Figure 2. EDD mass spectrum complexity increases when product ions accompanied by $\mathrm{SO}_{3}$ loss are present. (a) EDD of the [M $-3 \mathrm{H}]^{3-}$ of DS dp8 produces a more complex mass spectrum than (b) EDD of $[\mathrm{M}-5 \mathrm{H}]^{5-}$. 


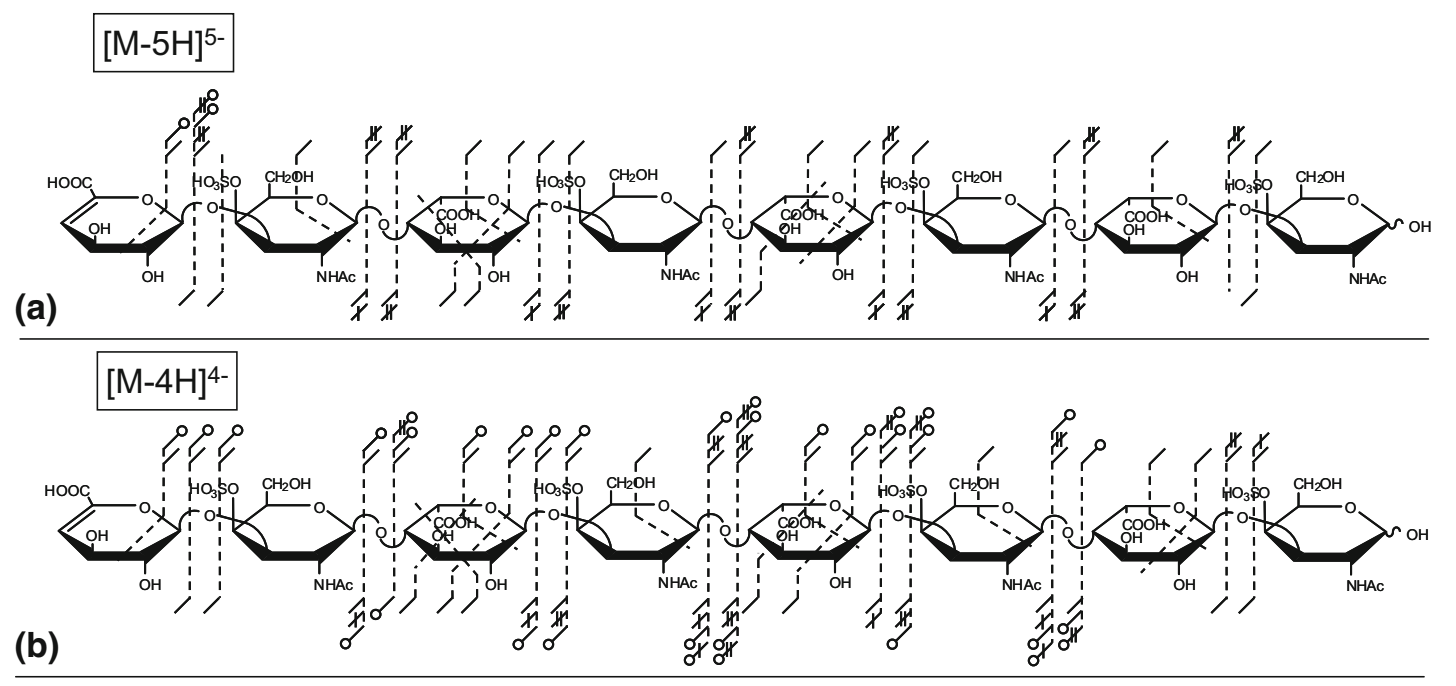

$[\mathrm{M}-3 \mathrm{H}]^{3-}$

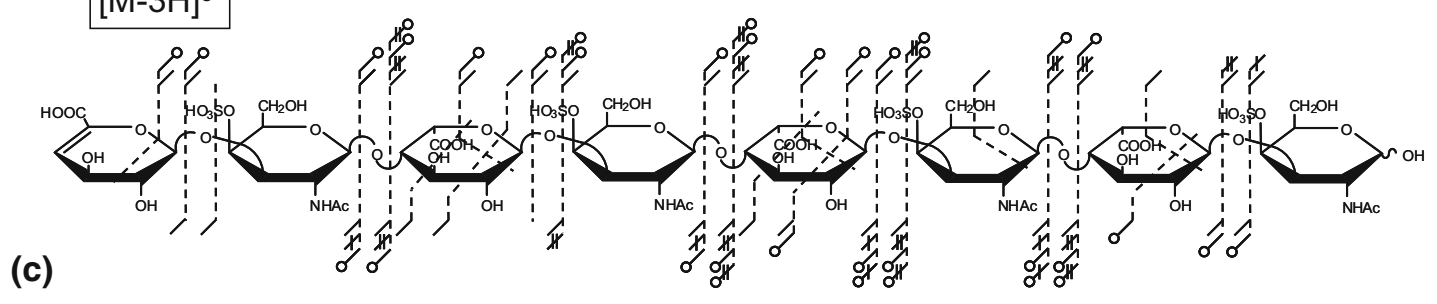

Figure 3. Influence of precursor ion charge on EDD of DS dp8. Product ions observed from EDD of (a) the $[\mathrm{M}-5 \mathrm{H}]^{5-}$ precursor ion, (b) the $[\mathrm{M}-4 \mathrm{H}]^{4-}$ precursor ion, and (c) the $[\mathrm{M}-3 \mathrm{H}]^{3-}$ precursor ion of DS dp8.

$-4 \mathrm{H}]^{4-}$ results in 34 of the 87 products being accompanied by $\mathrm{SO}_{3}$ loss. In contrast to this, 3 of the 56 products from EDD of $[\mathrm{M}-5 \mathrm{H}]^{5-}$ are accompanied by $\mathrm{SO}_{3}$ loss. Most glycosidic cleavages of the $3^{-}$or $4^{-}$ precursor occur with loss of $\mathrm{SO}_{3}$, but are absent for the $5^{-}$charge state. Abundant and similar glycosidic and cross-ring fragmentations are observed for EDD of all charge states. For EDD of $[\mathrm{M}-3 \mathrm{H}]^{3-},[\mathrm{M}-4 \mathrm{H}]^{4-}$, and $[\mathrm{M}-5 \mathrm{H}]^{5-}$, cleavage of most glycosidic bonds is observed. EDD of $[\mathrm{M}-5 \mathrm{H}]^{5-}$ and $[\mathrm{M}-3 \mathrm{H}]^{3-}$ produces 26 of the 28 possible products (Figure $3 a$ and c, respectively), whereas EDD of $[\mathrm{M}-4 \mathrm{H}]^{4-}$ precursor produces all 28 possible glycosidic products (Figure $3 b$ ). Differences in the number of observed glycosidic cleavages are attributed to the low abundance of the product ion, or overlap of the product ion with the precursor ion. Glycosidic bond cleavages accompanied by loss of one or two additional hydrogen atoms are observed for EDD of all charge states. Specifically, we observed $\mathrm{B}-\mathrm{H}, \mathrm{C}-2 \mathrm{H}, \mathrm{Y}-2 \mathrm{H}$, and $\mathrm{Z}-2 \mathrm{H}$, which we refer to as $\mathrm{B}^{\prime}, \mathrm{C}^{\prime \prime}, \mathrm{Y}^{\prime \prime}$, and $\mathrm{Z}^{\prime \prime}$, respectively. We have previously suggested radical mechanisms for the formation of these ions and found them useful for analyzing structural features, such as distinguishing IdoA from GlcA [24].

Previous results from CAD of sulfated GAGs suggest that the sulfate group readily loses $\mathrm{SO}_{3}$ when it is protonated [25]. Because sulfate is more acidic than carboxylate in solution, sulfate groups will be ionized in preference to carboxyl groups in solution. Products observed from EDD of DS dp8 indicate that these sites of charge are preserved as the molecule moves from solution to the gas phase and, as a result, sulfate groups will ionize in preference to carboxyl groups. Therefore it is expected that the $[\mathrm{M}-5 \mathrm{H}]^{5-}$ precursor will have all four sulfate residues charged plus one carboxylate group charged. Electron detachment is expected to occur more readily from the carboxylate anion because it requires approximately $1.2 \mathrm{eV}$ less energy than from a sulfate anion [23]. For the $3^{-}$and $4^{-}$precursor ions only sulfates will be ionized, and detachment will occur from the sulfate group. In support of this, EDD of [M $5 \mathrm{H}]^{5-}$ produces the charge-reduced species minus $\mathrm{CO}_{2}$ $\left(\left[\mathrm{M}-5 \mathrm{H}-\mathrm{CO}_{2}\right]^{4-\bullet}\right)$ and not the charge-reduced species minus $\mathrm{SO}_{3}\left(\left[\mathrm{M}-5 \mathrm{H}-\mathrm{SO}_{3}\right]^{4-\bullet}\right)$, indicating a preference for radical site formation at the carboxylate anion. Conversely, for EDD of $[\mathrm{M}-3 \mathrm{H}]^{3-}$ and $[\mathrm{M}-$ $4 \mathrm{H}]^{4-}$, the charge-reduced species minus $\mathrm{SO}_{3}([\mathrm{M}-3 \mathrm{H}$ $\left.-\mathrm{SO}_{3}\right]^{2-\bullet}$ and $\left[\mathrm{M}-4 \mathrm{H}-\mathrm{SO}_{3}\right]^{3-\bullet}$, respectively) is observed, but not the charge-reduced species minus $\mathrm{CO}_{2}$. These data suggest that electron detachment from a sulfate anion produces a sulfate radical that readily loses $\mathrm{SO}_{3}$ from EDD product ions, whereas electron detachment from a carboxylate anion does not promote the loss of $\mathrm{SO}_{3}$. Therefore, if the charge on the precursor ion is greater than the number of sulfate groups, at least one ionized carboxyl group is present and available as a radical site after electron detachment, and $\mathrm{SO}_{3}$ loss will be greatly reduced in EDD fragmentation. 
The pattern of $\mathrm{SO}_{3}$ loss from the charge-reduced species suggests that the initial site of radical formation occurs on a sulfate group of the GalNAc4S residues for the $3^{-}$and $4^{-}$charge states of DS dp8, and on a carboxylate group of IdoA residues for the $5^{-}$charge state of DS dp8. The majority of the cross-ring fragmentation products that are observed, however, originate across IdoA residues for all the charge states of the precursor. The preferential fragmentation of the acidic residues (IdoA) over fragmentation of basic residues (GalNAc4S), regardless of the initial site of electron detachment, can be rationalized by radical site migration from GalNAc4S to IdoA, for example, by radical site initiated hydrogen rearrangement. Another explanation for these data is that many of the "EDD" products do not arise from radical site initiated fragmentation, but are a result of ion activation from the interaction of the precursor ions with the $19 \mathrm{eV}$ electrons [29-31]. Clearly, the loss of $\mathrm{CO}_{2}$ or $\mathrm{SO}_{3}$ from the charge-reduced species is a radical-driven process because these products are strongly influenced by the initial site of radical formation. Other products appear to arise both from fragmentation of the odd-electron charge-reduced species as well as from activation of the even-electron precursor ion. We have recently examined the electron-induced dissociation (EID) of singly charged GAG tetrasaccharides, for which all products must come from an even-electron precursor (unpublished observations). Many cross-ring fragmentation products of the hexuronic acid residues were found in the EID mass spectrum that were not found in the IRMPD mass spectrum of the same precursor ion. Previously, we had proposed the preponderance of cross-ring fragmentation of the hexuronic acid residues over amino sugars in heparan sulfate tetrasaccharides [23] and dermatan sulfate oligosaccharides [22] was related to radical-driven fragmentation processes originating from a carboxy-radical. However, the newer EID data suggest that hexuronic acid residues are more labile, and that fragmentation of the hexuronic acid residues occurs by electron activation of the evenelectron precursor ion (EID) as well as by radical-driven fragmentation (EDD).

The gas-phase ion conformation of proteins has been shown to influence the products observed by ECD. The combination of IRMPD with ECD, known as activated ion ECD (AI-ECD) [32], has been shown to increase the number of backbone cleavages by ECD, and this effect is also observed by increasing the precursor ion charge state [33]. This increase in fragmentation has been proposed to occur from a change in ion conformation that results from breaking intramolecular noncovalent bonds, producing a more extended structure. To examine the possibility that conformation affects fragmentation for GAG oligomers, activated ion EDD (AI-EDD) was performed on the $[\mathrm{M}-4 \mathrm{H}]^{4-}$ precursor ion using $\mathrm{CO}_{2}$ laser irradiation to warm the ions to the threshold of fragmentation, followed by irradiation with electrons. Although the $\mathrm{S} / \mathrm{N}$ of some product ions in- creased slightly, AI-EDD does not influence the type or relative abundance of the observed products, specifically products accompanied by $\mathrm{SO}_{3}$ loss (data not shown). Therefore, the difference in $\mathrm{SO}_{3}$ loss in the $3^{-}$ and $4^{-}$versus $5^{-}$charge states appears to be a result of electron detachment from a carboxylate anion and not attributed to a change in gas-phase conformation.

\section{EDD of DS dp8 with Sodium Cations}

The loss of $\mathrm{SO}_{3}$ by MS/MS of sulfated GAG oligosaccharides complicates the mass spectrum and reduces its analytical utility. Thus, controlling $\mathrm{SO}_{3}$ loss is important for the analysis of GAG oligosaccharides. The results of the charge state dependence studies show that $\mathrm{SO}_{3}$ loss is reduced when at least one carboxyl group is ionized in the precursor ion. As an alternative to dissociation of higher charge states, which may not have substantial abundance by ESI, we have investigated the replacement of protons by sodium. In such ions, the charge state will be smaller than the number of ionized sites in the precursor. As Figure 1 shows, the $[\mathrm{M}-5 \mathrm{H}]^{5-}$ ion is half as abundant as the $[\mathrm{M}-5 \mathrm{H}+\mathrm{Na}]^{4-}$. Both have five ionized sites and will therefore have an ionized carboxyl group available for electron detachment, providing a way to achieve a higher degree of ionization with precursor ions of a lower overall charge.

Products from EDD of the $[\mathrm{M}-5 \mathrm{H}+\mathrm{Na}]^{4-}$ precursor ion of DS dp8 are shown in Figure 4a (mass spectrum provided as supplemental data, which can be found in the electronic version of this article). When sodium is present in the precursor ion, product ions may occur as protonated or sodium cationized products. Product ions that are observed with sodium are indicated by a number above the fragment notation, with this number indicating the number of sodium cations in the product ion. For the work presented here, products containing sodium are described as the fragment plus the number of sodium cations, such as ${ }^{0,2} \mathrm{X}_{7}+$ $\mathrm{Na}$. EDD of the $[\mathrm{M}-5 \mathrm{H}+\mathrm{Na}]^{4-}$ precursor ion of DS dp8 produces abundant glycosidic and cross-ring fragmentations similar to EDD of the noncationized (i.e., $3^{-}$, $4^{-}$, and $5^{-}$) precursor ions of DS dp8. Glycosidic cleavages accompanied by the loss of 1 or 2 hydrogen atoms are also observed. Compared to EDD of [M $4 \mathrm{H}]^{4-}$ (Figure $2 \mathrm{~b}$ ), EDD of $[\mathrm{M}-5 \mathrm{H}+\mathrm{Na}]^{4-}$ results in a significant decrease in product ions accompanied by $\mathrm{SO}_{3}$ loss. When compared to the product ions observed from EDD of the $3^{-}, 4^{-}$, and $5^{-}$precursor ions of DS dp8 (Figure 2), the products observed from EDD of the $[\mathrm{M}-5 \mathrm{H}+\mathrm{Na}]^{4-}$ precursor ion resemble more closely the products observed from EDD of the $[\mathrm{M}-5 \mathrm{H}]^{5-}$ precursor ion. For example, cross-ring cleavages occur primarily on IdoA residues. Also, the charge-reduced species minus $\mathrm{CO}_{2},\left[\mathrm{M}-5 \mathrm{H}+\mathrm{Na}-\mathrm{CO}_{2}\right]^{3-\bullet}$, and not $\mathrm{SO}_{3}$ is observed. $\mathrm{SO}_{3}$ loss accompanying other fragmentation is greatly reduced in EDD of both $[\mathrm{M}-5 \mathrm{H}]^{5-}$ and $[\mathrm{M}-5 \mathrm{H}+\mathrm{Na}]^{4-}$, and the small number of products accompanied by $\mathrm{SO}_{3}$ loss occur near the NRE 

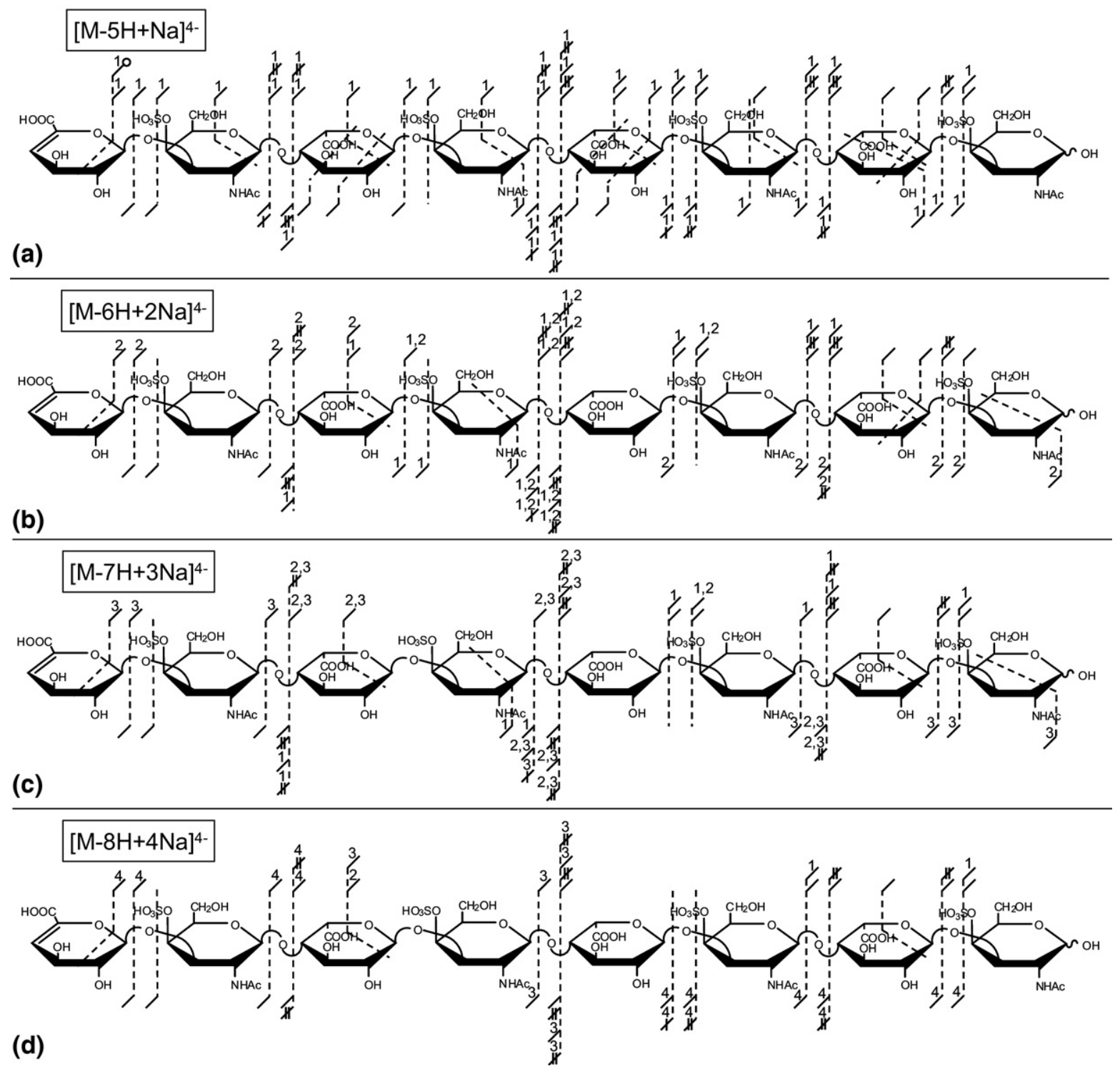

Figure 4. Product ions observed from EDD of the (a) $[\mathrm{M}-5 \mathrm{H}+\mathrm{Na}]^{4-}$, (b) $[\mathrm{M}-6 \mathrm{H}+2 \mathrm{Na}]^{4-}$, (c) $[\mathrm{M}-7 \mathrm{H}+3 \mathrm{Na}]^{4-}$, and (d) $[\mathrm{M}-8 \mathrm{H}+4 \mathrm{Na}]^{4-}$ precursor ions of DS dp8.

of the octasaccharide for both precursors. For example, 34 of the 87 observed products from EDD of the [M $4 \mathrm{H}]^{4-}$ precursor ion are accompanied by $\mathrm{SO}_{3}$ loss, whereas 3 of the 56 and 1 of the 70 observed products from EDD of the $[\mathrm{M}-5 \mathrm{H}]^{5-}$ and $[\mathrm{M}-5 \mathrm{H}+\mathrm{Na}]^{4-}$ precursor ions, respectively, are accompanied by $\mathrm{SO}_{3}$ loss. Together, these data suggest a total of five ionized sites on DS dp8, with at least one ionized site on a carboxy group. These data are consistent with our proposal that electron detachment preferentially occurs from the carboxylate anion, with EDD of [M $-5 \mathrm{H}+$ $\mathrm{Na}]^{4-}$ exhibiting a significant decrease in $\mathrm{SO}_{3}$ loss and fragmentation similar to EDD of $[\mathrm{M}-5 \mathrm{H}]^{5-}$. These observations suggest $\mathrm{SO}_{3}$ loss is suppressed when the total number of ionized sites on the GAG is one more than the number of sulfate groups. In further support of this observation, a significant decrease in $\mathrm{SO}_{3}$ loss is observed for EDD of $[\mathrm{M}-5 \mathrm{H}+2 \mathrm{Na}]^{3-}$ when compared to the EDD data of $[\mathrm{M}-4 \mathrm{H}+\mathrm{Na}]^{3-}$ (data not shown).

Additional replacement of protons by sodium cations can be used to increase the number of ionized sites. We have examined the EDD of DS dp8 with up to eight ionized acidic groups. Products from the EDD of the [M $-6 \mathrm{H}+2 \mathrm{Na}]^{4-},[\mathrm{M}-7 \mathrm{H}+3 \mathrm{Na}]^{4-}$, and $[\mathrm{M}-8 \mathrm{H}+$ $4 \mathrm{Na}]^{4-}$ precursor ions are shown in Figure $4 \mathrm{~b}$ and $\mathrm{c}$, respectively (see supplemental data for EDD mass spectra). As shown in Figure 4, increasing the number of sodium cations, and thus the number of ionized sites on the DS dp8 precursor ion, decreases the number of observed glycosidic and cross-ring fragmentations. For the $4^{-}$ion of DS dp8 with $1-4$ sodium cations, the charge reduced species minus $\mathrm{CO}_{2}$ is observed for all ions, indicating preference for electron detachment at carboxylate on IdoA residues. Although increasing the 


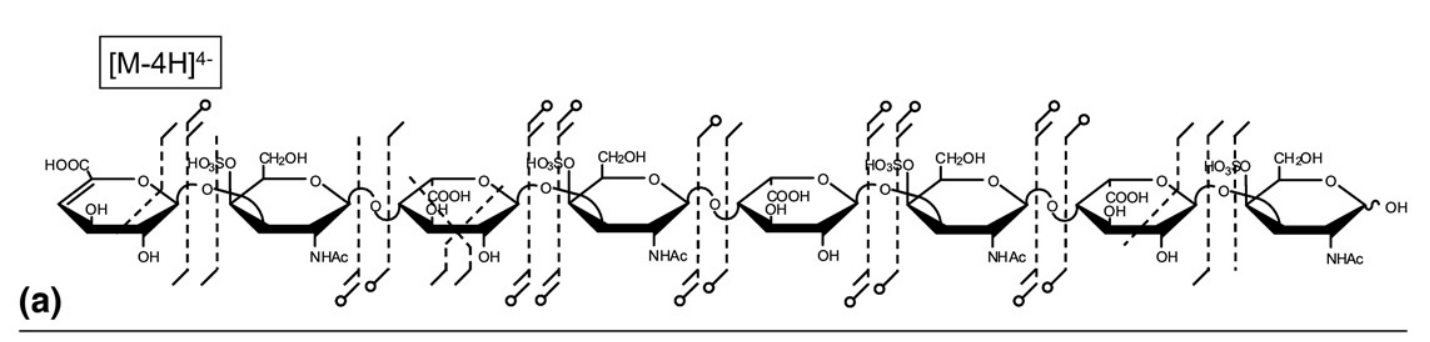

(a)

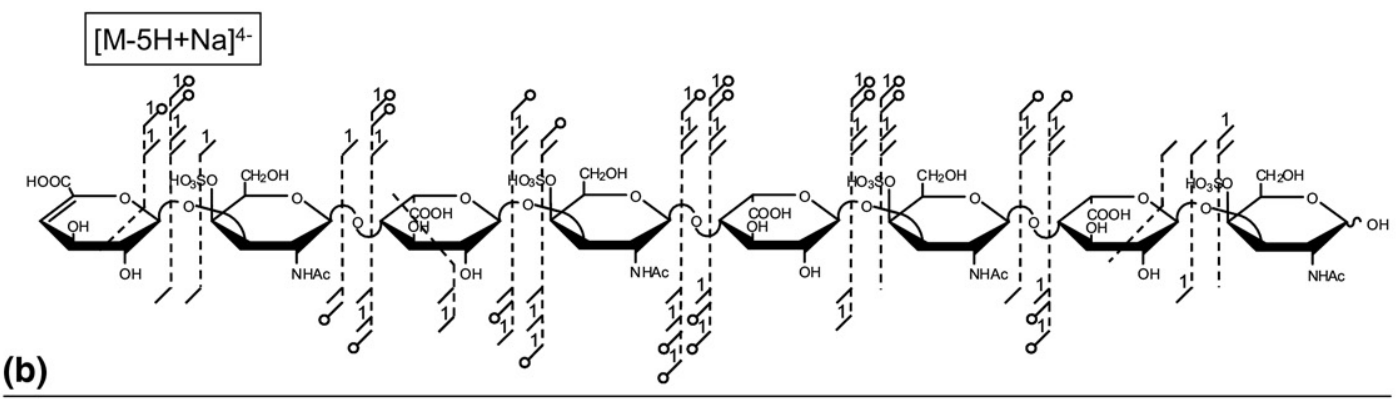

(b)

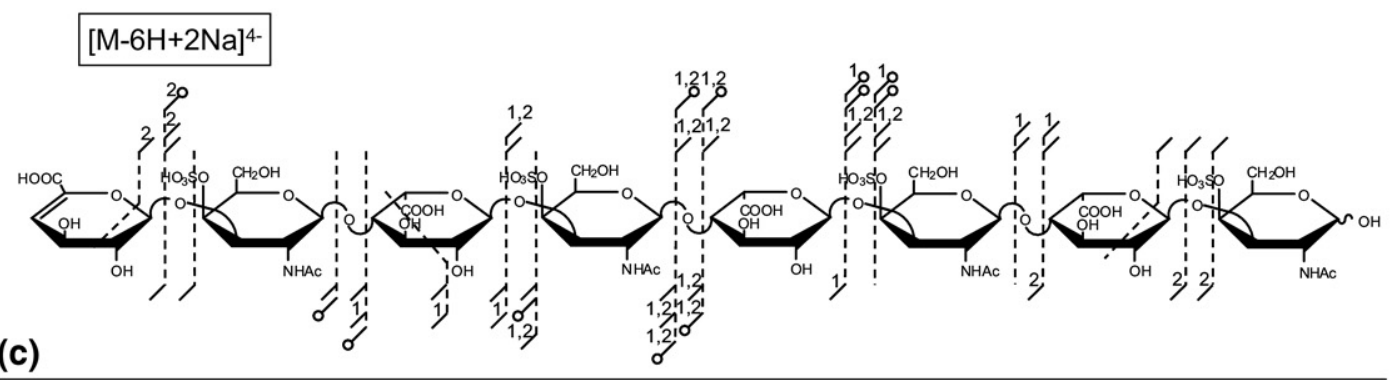

(c)
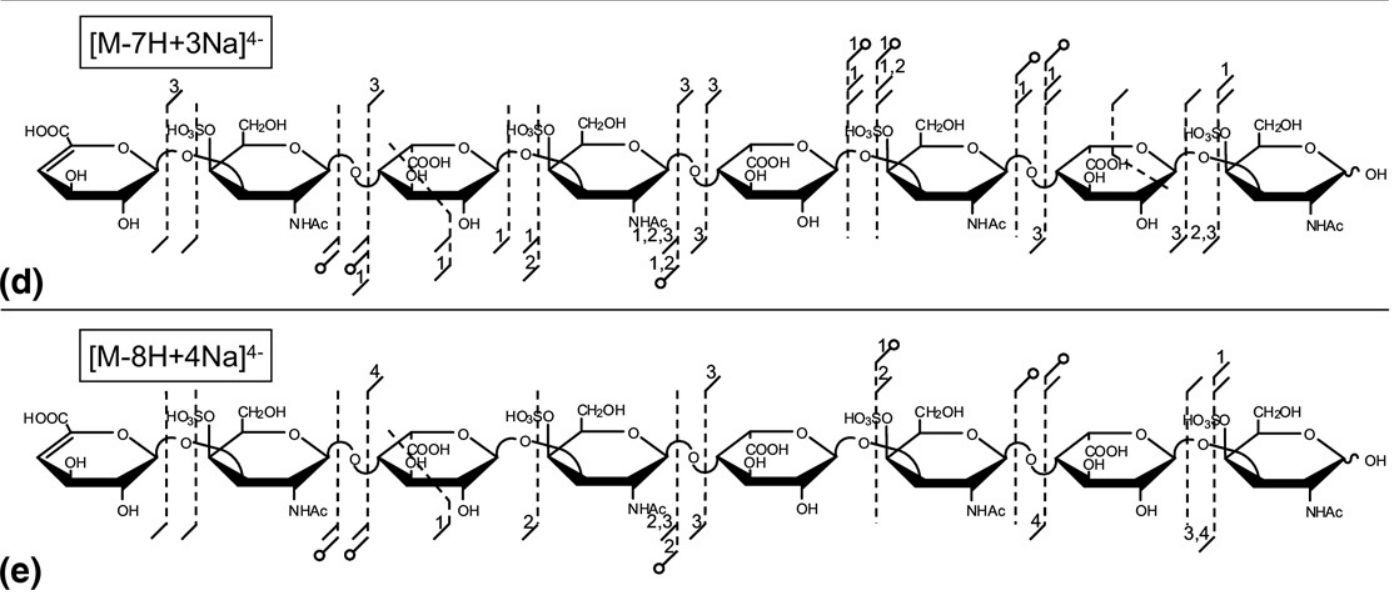

Figure 5. Product ions observed from IRMPD of the (a) $[\mathrm{M}-4 \mathrm{H}]^{4-}$, (b) $[\mathrm{M}-5 \mathrm{H}+\mathrm{Na}]^{4-}$, (c) $[\mathrm{M}$ $-6 \mathrm{H}+2 \mathrm{Na}]^{4-}$, (d) $[\mathrm{M}-7 \mathrm{H}+3 \mathrm{Na}]^{4-}$, and (e) $[\mathrm{M}-8 \mathrm{H}+4 \mathrm{Na}]^{4-}$ precursor ions of DS dp8.

ionization state of the molecule such that one carboxylate is charged benefits fragmentation by decreasing $\mathrm{SO}_{3}$ loss, further ionization of the GAG with sodium cations reduces EDD fragmentation. The decrease in fragmentation suggests that carboxyl hydrogens may play a role in the mechanism of cross-ring fragmentation, perhaps via hydrogen rearrangement reactions.

\section{IRMPD of DS dp8 with Sodium Cations}

$\mathrm{SO}_{3}$ loss during electron activation methods such as EDD or EID differs from that observed during activa- tion of even-electron ions by threshold or low-energy methods. Previous work by Zaia and coworkers suggests that sulfate groups are most labile and readily undergo loss of $\mathrm{SO}_{3}$ during CAD when protonated [25]. Although $\mathrm{SO}_{3}$ loss can be minimized and glycosidic cleavages maximized by increasing the charge state so that all sulfate groups are charged, the abundance of precursor ions in which all sulfates are charged may be too small to be useful for MS/MS. The addition of sodium cations to the ESI solution allows IRMPD to be applied to more ionized sulfated GAGs. Products resulting from IRMPD of the $[\mathrm{M}-4 \mathrm{H}]^{4-},[\mathrm{M}-5 \mathrm{H}+$ 
$\mathrm{Na}]^{4-},[\mathrm{M}-6 \mathrm{H}+2 \mathrm{Na}]^{4-},[\mathrm{M}-7 \mathrm{H}+3 \mathrm{Na}]^{4-}$, and $[\mathrm{M}-$ $8 \mathrm{H}+4 \mathrm{Na}]^{4-}$ precursor ions of DS dp8 are shown in Figure $5 \mathrm{a}-\mathrm{c}$, respectively. Compared to EDD of the same precursor ions (Figures $2 \mathrm{a}$ and $4 \mathrm{a}-\mathrm{c}$ ), IRMPD produces fewer glycosidic and cross-ring cleavages as well as more abundant $\mathrm{SO}_{3}$ loss. Unlike EDD, IRMPD produces some product ions that are observed only with $\mathrm{SO}_{3}$ loss. However, product ion $\mathrm{SO}_{3}$ loss decreases as the cationization of the precursor ion increases; for example, IRMPD of the $[\mathrm{M}-4 \mathrm{H}]^{4-}$ precursor ion produces 18 products accompanied by $\mathrm{SO}_{3}$ loss, whereas IRMPD of the $[\mathrm{M}-8 \mathrm{H}+4 \mathrm{Na}]^{4-}$ produces six products accompanied by $\mathrm{SO}_{3}$ loss. These results are similar to the observations by Zaia et al. [25], suggesting that ionization of the sulfate groups prevents loss of $\mathrm{SO}_{3}$ for ion activation via threshold dissociation. The number of glycosidic bond and cross-ring cleavages produced by IRMPD decreases when the ionization of the GAG is increased using sodium cations, similar to the observation for EDD. For example, IRMPD of the [M $4 \mathrm{H}]^{4-}$ precursor ion produces a total of 41 glycosidic and cross-ring cleavages, whereas IRMPD of the [M $8 \mathrm{H}+4 \mathrm{Na}]^{4-}$ produces 23 glycosidic and cross-ring cleavages.

\section{Conclusions}

The ionization state of a sulfated GAG affects the number of ionized sites available for electron detachment. Since electron detachment occurs at a site of negative charge, the pattern of $\mathrm{SO}_{3}$ loss in EDD of sulfated GAGs is dependent on the number of ionized sites on the sulfated GAG. When electron detachment occurs at a sulfate anion, many product ions are accompanied by loss of $\mathrm{SO}_{3}$. When electron detachment occurs at a carboxylate anion there is a significant decrease in the number of product ions accompanied by loss of $\mathrm{SO}_{3}$. Increasing the degree of ionization can be achieved either by increasing the precursor ion charge state or by replacing protons with sodium cations. Both methods can be used to ensure ionization of a carboxylate group. For EDD of sulfated GAGs, $\mathrm{SO}_{3}$ loss is minimized if the ionization state of the sulfated GAG is equal to one more than the number of sulfate groups. Further increasing the ionization state of the molecule so that more carboxylate groups are charged eliminates $\mathrm{SO}_{3}$ loss by EDD, but also decreases the number of glycosidic and cross-ring cleavages. For IRMPD of sulfated GAGs, increasing the ionization state of GAG precursor ions by replacement of protons with sodium cations decreases $\mathrm{SO}_{3}$ loss, but also decreases glycosidic and cross-ring fragmentations.

\section{Acknowledgments}

The authors acknowledge the seminal contributions of Roman Zubarev to the field of electron-ion interactions, and offer congratulations on his selection as a Biemann awardee, and gratefully acknowledge financial support from the National Institutes of Health Grant 2R01-GM038060-16.

\section{References}

1. Linhardt, R. J.; Toida, T. Role of Glycosaminoglycans in Cellular Communication. Acc. Chem. Res. 2004, 37, 431-438.

2. Gotte, M. Syndecans in Inflammation. FASEB J. 2003, 17, 575-591.

3. Fannon, M.; Forsten, K. E.; Nugent, M. A. Potentiation and Inhibition of bFGF Binding by Heparin: A Model for Regulation of Cellular Response. Biochemistry 2000, 39, 1434-1445.

4. Wu, Z. L.; Zhang, L.; Yabe, T.; Kuberan, B.; Beeler, D. L.; Love, A. Rosenberg, R. D. The Involvement of Heparan Sulfate (HS) in FGF1/ HS/FGFR1 Signaling Complex. I. Biol. Chem. 2003, 278, 17121-17129.

5. Sadir, R.; Imberty, A.; Baleux, F.; Lortat-Jacob, H. Heparan Sulfate/ Heparin Oligosaccharides Protect Stromal Cell-derived Factor-1 (SDF1)/CXCL12 against Proteolysis Induced by CD26/Dipeptidyl Peptidase IV. J. Biol. Chem. 2004, 279, 43854-43860.

6. Iozzo, R. V.; San Antonio, J. D. Heparan Sulfate Proteoglycans: Heavy Hitters in the Angiogenesis Arena. J. Clin. Invest. 2001, 108, 349-355.

7. Batinic, D.; Robey, F. A. The V3 Region of the Envelope Glycoprotein of Human Immunodeficiency Virus Type 1 Binds Sulfated Polysaccharides and CD4-derived Synthetic Peptides. J. Biol. Chem. 1992, 267, 6664-6671.

8. Chen, Y.; Maguire, T.; Hileman, R. E.; Fromm, J. R.; Esko, J. D.; Linhardt, R. J.; Marks, R. M. Dengue Virus Infectivity Depends on Envelope Protein Binding to Target Cell Heparan Sulfate. Nat. Med. 1997, 3 , $866-871$.

9. Williams, R. K.; Straus, S. E. Specificity and Affinity of Binding of Herpes Simplex Virus Type 2 Glycoprotein B to Glycosaminoglycans. J. Virol. 1997, 71, 1375-1380.

10. Liu, D. F.; Shriver, Z.; Gi, Y. W.; Venkataraman, G.; Sasisekharan, R. Dynamic Regulation of Tumor Growth and Metastasis by Heparan Sulfate Glycosaminoglycans. Semin. Thromb. Hemost. 2002, 28, 67-78.

11. Perrimon, N.; Bernfield, M. Cellular Functions of Proteoglycans-An Overview. Semin. Cell. Dev. Biol. 2001, 12, 65-67.

12. Horne, A.; Gettins, P. H. 1-NMR Spectral Assignments for 2 Series of Heparin-Derived Oligosaccharides. Carbohydr. Res. 1992, 225, 43-57.

13. Chi, L. L.; Amster, J.; Linhardt, R. J. Mass Spectrometry for the Analysis of Highly Charged Sulfated Carbohydrates. Curr. Anal. Chem. 2005, 1, 223-240.

14. Dai, Y.; Whittal, R. M.; Bridges, C. A.; Isogai, Y.; Hindsgaul, O.; Li, L. Matrix-Assisted Laser Desorption Ionization Mass Spectrometry for the analysis of monosulfated oligosaccharides. Carbohydr. Res. 1997, 304, 1-9.

15. Miller, M. J. C.; Costello, C. E.; Malmstrom, A.; Zaia, J. A Tandem Mass Spectrometric Approach to Determination of Chondroitin/Dermatan Sulfate Oligosaccharide Glycoforms. Glycobiology 2006, 16, 502-513.

16. Reinhold, V. N.; Carr, S. A.; Green, B. N.; Petitou, M.; Choay, J.; Sinay, P. Structural Characterization of Sulfated Glycosaminoglycans by FastAtom-Bombardment Mass-Spectrometry-Application to Heparin Fragments Prepared by Chemical Synthesis. Carbohydr. Res. 1987, 161 305-313.

17. Saad, O. M.; Leary, J. A. Compositional Analysis and Quantification of Heparin and Heparan Sulfate by Electrospray Ionization Ion Trap Mass Spectrometry. Anal. Chem. 2003, 75, 2985-2995.

18. Saad, O. M.; Leary, J. A. Heparin Sequencing Using Enzymatic Digestion and ESI-MS with HOST: A Heparin/HS Oligosaccharide Sequencing Tool. Anal. Chem. 2005, 77, 5902-5911.

19. Zaia, J.; Li, X.-Q.; Chan, S.-Y.; Costello, C. E. Tandem Mass Spectrometric Strategies for Determination of Sulfation Positions and Uronic Acid Epimerization in Chondroitin Sulfate Oligosaccharides. J. Am. Soc. Mass Spectrom. 2003, 14, 1270-1281.

20. Zaia, J.; McClellan, J. E.; Costello, C. E. Tandem Mass Spectrometric Determination of the $4 \mathrm{~S} / 6 \mathrm{~S}$ Sulfation Sequence in Chondroitin Sulfate Oligosaccharides. Anal. Chem. 2001, 73, 6030-6039.

21. Budnik, B. A.; Haselmann, K. F.; Zubarev, R. A. Electron Detachment Dissociation of Peptide Di-Anions: An Electron-Hole Recombination Phenomenon. Chem. Phys. Lett. 2001, 342, 299-302.

22. Wolff, J. J.; Laremore, T. N.; Busch, A. M.; Linhardt, R. J.; Amster, I. J Electron Detachment Dissociation of Dermatan Sulfate Oligosaccharides. J. Am. Soc. Mass Spectrom. 2008, 19, 294-304.

23. Wolff, J. J.; Amster, I. J.; Chi, L.; Linhardt, R. J. Electron Detachment Dissociation of Glycosaminoglycan Tetrasaccharides. J. Am. Soc. Mass Spectrom. 2007, 18, 234-244.

24. Wolff, J. J.; Chi, L. L.; Linhardt, R. J.; Amster, I. J. Distinguishing Glucuronic from Iduronic Acid in Glycosaminoglycan Tetrasaccharides by Using Electron Detachment Dissociation. Anal. Chem. 2007, 79, 2015-2022.

25. Zaia, J.; Costello, C. E. Tandem Mass Spectrometry of Sulfated HeparinLike Glycosaminoglycan Oligosaccharides. Anal. Chem. 2003, 75, 2445-2455.

26. Pervin, A.; Gallo, C.; Jandik, K. A.; Han, X.-J.; Linhardt, R. J. Preparation and Structural Characterization of Large Heparin-Derived Oligosaccharides. Glycobiology 1995, 5, 83-95.

27. Heck, A. J. R.; de Koning, L. J.; Pinkse, F. A.; Nibbering, N. M. M. Mass-Specific Selection of Ions in Fourier-Transform Ion Cyclotron Resonance Mass Spectrometry. Unintentional off-Resonance Cyclotron Excitation of Selected Ions. Rapid Commun. Mass Spectrom. 1991, 5, 406-414. 
28. Domon, B.; Costello, C. E. A Systematic Nomenclature for Carbohydrate Fragmentations in FAB-MS/MS Spectra of Glycoconjugates. Glycoconjugate J. 1988, 5, 397-409.

29. Budnik, B. A.; Haselmann, K. F.; Elkin, Y. N.; Gorbach, V. I.; Zubarev, R. A. Applications of Electron-Ion Dissociation Reactions for Analysis of Polycationic Chitooligosaccharides in Fourier Transform Mass Spectrometry. Anal. Chem. 2003, 75, 5994-6001.

30. Cody, R. B.; Freiser, B. S. Electron Impact Excitation of Ions from Organics: An Alternative to Collision Induced Dissociation. Anal. Chem. 1979, 51, 547-551.
31. Cody, R. B.; Freiser, B. S. Electron Impact Excitation of Ions in Fourier Transform Mass Spectrometry. Anal. Chem. 1987, 59, 1054-1056.

32. Horn, D. M.; Ge, Y.; McLafferty, F. W.; Activated Ion. Electron Capture Dissociation for Mass Spectral Sequencing of Larger (42 kDa) Proteins. Anal. Chem. 2000, 72, 4778-4784.

33. Sze, S. K.; Ge, Y.; Oh, H. B.; McLafferty, F. W. Top-Down Mass Spectrometry of a 29-kDa Protein for Characterization of any Posttranslational Modification to within One Residue. yyProc. Natl. Acad. Sci. U.S.A. 2002, 99, 1774-1779. 